\title{
Effect of Using Twisted Tape Inserts on Performance of Compound Parabolic Concentrators
}

\author{
M. H. Eldakamawy, A. Hanafi, and M. A. Kassem
}

\begin{abstract}
Modeling of a compound parabolic collector with bare tubular absorber was performed, regarding its geometrical, optical and thermal features. The developed model was validated via two recent experiments showing accepted agreement with the experimental results. After that we studied the effect of inserting different configurations of twisted tapes in the absorber tube on the thermal efficiency, the pumping power and the thermal performance factor. It was concluded that inserting twisted tapes is much favorable when the flow was laminar rather than being in transition or turbulent regimes.
\end{abstract}

Index Terms-Compound parabolic concentrators, heat transfer enhancement, modeling, swirl flow.

\section{INTRODUCTION}

Investigation of the characteristics of a compound parabolic concentrator (CPC) with tubular absorber was carried out [1]-[3]. However, oversimplification was an obvious drawback, either by neglecting the interaction of the reflector and treating the CPC absorber tube as an ordinary horizontal one subjected to natural convection heat loss [1], or dealing with the CPC cavity as an eccentric tube inside a horizontal annulus [2], or using discrete values for average number of internal reflections imported from CPC with flat absorber [3]. Yet, no consideration was given to the effect of using heat transfer enhancement techniques, like swirlers insertion, on CPC thermal performance.

In the first section a detailed study of CPC geometrical, optical and thermal aspects along with the governing equations are demonstrated. The necessary validation is then provided through two previous experiments. After that various designs of twisted tape inserts were proposed showing their associated empirical equations for Nusselt number and friction factor. Finally, the effect of using swirlers on thermal efficiency, pumping power and thermal performance factor was discussed for various flow regimes.

\section{MODELING OF THE COMPOUND PARABOLIC CONCENTRATOR WITH TUBULAR ABSORBER}

\section{A. Geometrical Properties}

In the subsequent formulation, the symbols $\mathrm{A}$ and $\mathrm{T}$ stand for area and temperature, respectively. $\alpha, \rho, \tau$ and $\epsilon$ represent the absorptance, reflectance, transmittance and emittance, respectively, while the subscripts a, m, and $\mathrm{r}$ refer to the cover, reflector, and absorber, respectively. A

Manuscript received September 29, 2014; revised January 20, 2015.

The authors are with the Mechanical Power Department, Faculty of Engineering, Cairo University, Egypt (e-mail: m.eldakamawy@gmail.com, hanafi1946@yahoo.com, mahmoudkassem2@gmail.com). schematic of the CPC collector under investigation is shown in Fig. 1.

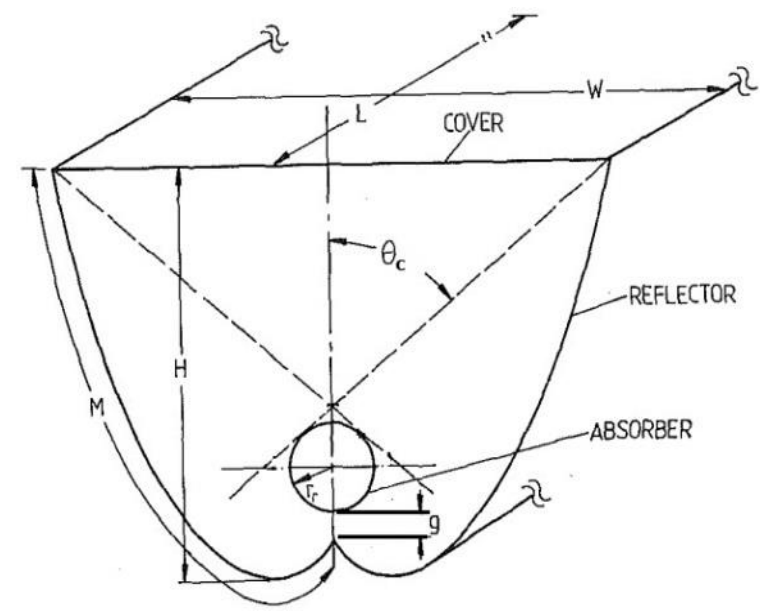

Fig. 1. CPC collector with non-evacuated tubular absorber [2]

Having the absorber radius $\left(R_{r}\right)$ and the acceptance half-angle $\left(\theta_{c}\right)$ known, we can plot the profile of the full (untruncated) $\mathrm{CPC}$, from which we can calculate the required aperture and reflector areas. Fig. 2 shows a full CPC with $\theta_{c}=$ $40^{\circ}$. Each side of the reflector has two segments which are represented by two distinct mathematical relations and join each other at point $P$. The first segment which starts from the bottom of the absorber to point $\mathrm{P}$, is the involute of the absorber's circular cross section. The second segment continues from point $\mathrm{P}$ to the top of the curve where it becomes parallel to the $\mathrm{Y}$ axis. $\mathrm{X}$ and $\mathrm{Y}$ coordinates, as a function of $\theta$, can be calculated from [4],

$$
\begin{gathered}
X=R_{r} \sin \theta-\rho \cos \theta \\
Y=-R_{r} \cos \theta-\rho \sin \theta
\end{gathered}
$$

where

$$
\rho(\theta)=\left\{\begin{array}{cl}
R_{r} \theta & ,|\theta| \leq \theta_{c}+\frac{\pi}{2} \\
\text { (the involute part of the curve) } & \\
R_{r}\left\{\frac{\theta+\theta_{c}+\left(\frac{\pi}{2}\right)-\cos \left(\theta-\theta_{c}\right)}{1+\sin \left(\theta-\theta_{c}\right)}\right\}, & \theta_{c}+\frac{\pi}{2} \leq \theta \leq \frac{3 \pi}{2}-\theta_{c}
\end{array}\right.
$$

After plotting, in a manner like shown in Fig. 3, the aperture width $(\mathrm{W})$ can be got and the aperture area, $A_{a}=\mathrm{WL}$, can be calculated, where $L$ is the collector length. To calculate the reflector area, $A_{m}=2 \mathrm{ML}$, we need to evaluate the reflector's arc length, $M$. Recalling the well-known formula for calculating any arc length in its parametric form,

$$
d s=\sqrt{\left(\frac{d x}{d t}\right)^{2}+\left(\frac{d y}{d t}\right)^{2}}
$$


where $x$ and $y$ are $f(t)$, and having $X$ and $Y$ as a function of $\theta$, then the first segment's length $\left(M_{1}\right)$ will be

$$
M_{1}=\int_{0}^{\theta_{c}+\frac{\pi}{2}} \sqrt{\left(\frac{d X}{d \theta}\right)^{2}+\left(\frac{d Y}{d \theta}\right)^{2}} \cdot d \theta, m
$$

Such integration can be easily done using any suitable software. Similarly, the second segment's length $\left(M_{2}\right)$ and the whole arc length $(M)$ will be

$$
\begin{gathered}
M_{2}=\int_{\theta_{c}+\frac{\pi}{2}}^{\frac{3 \pi}{2}-\theta_{c}} \sqrt{\left(\frac{d X}{d \theta}\right)^{2}+\left(\frac{d Y}{d \theta}\right)^{2}} \cdot d \theta, m \\
M=M_{1}+M_{2}, m
\end{gathered}
$$

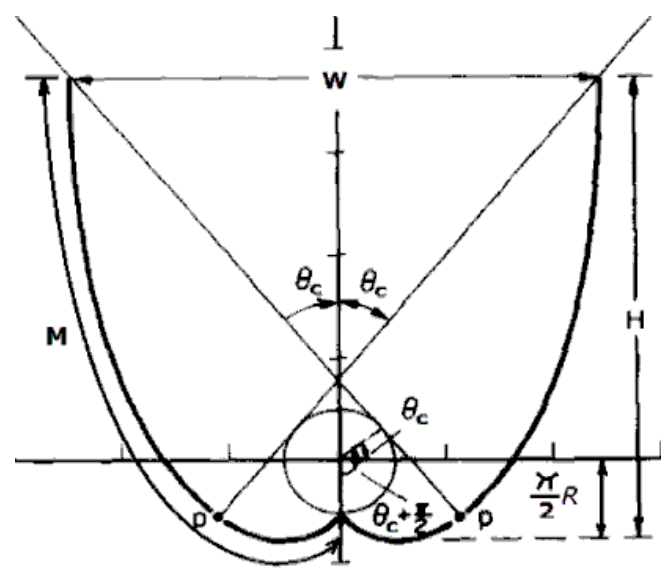

Fig. 2. Full (untruncated) CPC with tubular absorber and half-acceptance angle $=40^{\circ}[4]$.

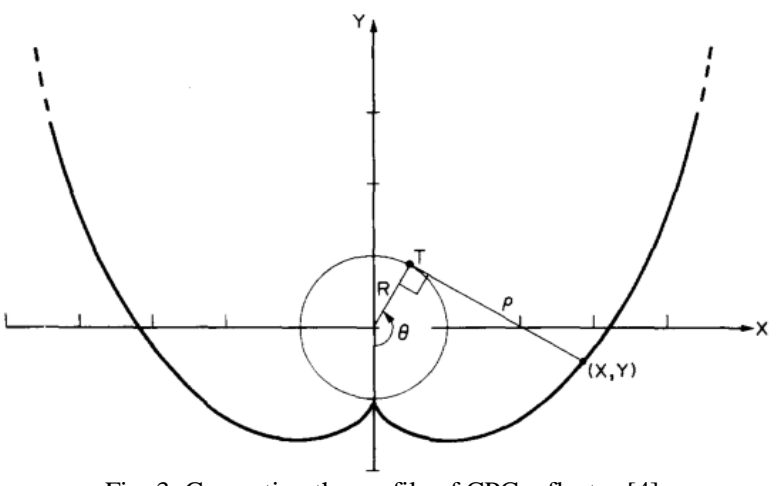

Fig. 3. Generating the profile of CPC reflector [4].

Recalling Fig. 2, at the end points of the two CPC reflector sides, the surfaces are nearly parallel to the CPC centerline, thus contributing a little to the concentration ratio and amount of radiation reaching the absorber. In practice we usually then truncate a CPC to about half of its full height to save reflector material and collector size with a small sacrifice in performance [5], [6].

If we deal with a truncated $\mathrm{CPC}$, the previous equations from (1) to (7) will still remain valid, except that the acceptance half-angle $\left(\theta_{c}\right)$ in the upper limit of the interval of the second segment (i.e: $3 \pi / 2-\theta_{c}$ ) will be replaced by the extreme edge ray angle $\left(\theta_{D}\right)$, as shown in Fig. 4. To calculate $\theta_{D}$, we must have the truncation ratio $\left(H_{t} / H\right)$. Then we can get the value of the truncated height $\left(H_{t}\right)$, where $H$ is the full CPC height. After that we equate (2) (Y coordinates) with $H_{t}-\frac{\pi}{2} R$, then evaluate $\theta_{D}$ which lies in the interval $\theta_{c}+\pi / 2 \leq \theta \leq 3 \pi / 2-\theta_{c}$.

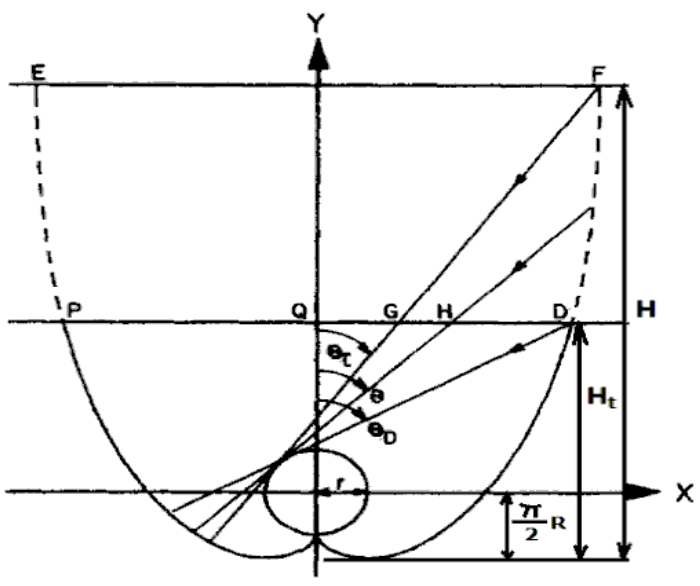

Fig. 4. The extreme edge ray angle $\left(\boldsymbol{\theta}_{\boldsymbol{D}}\right)$ of a truncated CPC [6].

\section{B. Optical Properties}

Suppose we have a light beam incident at an incidence angle $(\theta)$ on the aperture of a CPC collector. Firstly, if $\theta$ was less than $\theta_{c}$, then all light rays will reach the tubular absorber after making an average number of internal reflections $(\bar{n})$ by means of the reflector, as shown in the first two cases of Fig. 5. The calculation of $\bar{n}$ is of great importance because we need to know the fraction of incident light rays which will reach the absorber. Some rays will directly hit the absorber; others may undergo one or two reflections. As a result, we can compute the effective reflectivity (or sometimes we can call it transmissivity) of the reflector as $\rho_{m}^{\bar{n}}$, where $\rho_{m}$ is the actual reflectivity of the reflector's surface.

Despite the fact that $\bar{n}$ depends on the incidence angle, but for simplicity we'll deal with a single value for $\bar{n}$, representing an average over all rays within the field of view. By using an appropriate software, the average number of internal reflections done by sun rays within the acceptance angle can be calculated as found in [4],

$$
\bar{n}=\frac{\left(\theta_{c}+\frac{\pi}{2}\right)^{2}}{4 \pi}+\frac{\sqrt{2}}{2 \pi} \int_{\theta_{c}+\frac{\pi}{2}}^{\frac{3 \pi}{2}-\theta_{c}} \frac{\left[\theta_{c}+\frac{\pi}{2}+\theta-\cos \left(\theta-\theta_{C}\right)\right]\left[1-\sin \left(\frac{\theta-\theta_{c}-\frac{\pi}{2}}{2}\right)\right]}{\left[1+\sin \left(\theta-\theta_{c}\right)\right]^{3 / 2}}
$$

In case we have a truncated $\mathrm{CPC}, \theta_{c}$ in the upper limit of the integral will be replaced with $\theta_{D}$ similar to what we did previously. A check was done with numerical values of $\theta_{D}, \bar{n}$ and ratios of full $\mathrm{CPC}$ reflector area to truncated $\mathrm{CPC}$ reflector area, having $\theta_{c}=35^{\circ}$, and shown in Table I.

TABLE I: OPTICAL PROPERTIES OF TRUNCATED CPC WITH $\Theta_{\mathrm{C}}=35^{\circ}$
\begin{tabular}{|c|c|c|c|}
\hline$\theta_{D}$ (deg) & $C$ & $\bar{n}$ & $\begin{array}{c}A_{m}^{\text {full }} \\
/ A_{m}^{\text {trunc }}\end{array}$ \\
\hline 35 & 1.743 & 1.145 & 1.000 \\
\hline 50 & 1.670 & 1.011 & 1.379 \\
\hline 60 & 1.576 & 0.931 & 1.659 \\
\hline 70 & 1.468 & 0.857 & 1.963 \\
\hline 80 & 1.356 & 0.786 & 2.296 \\
\hline 90 & 1.242 & 0.719 & 2.664 \\
\hline
\end{tabular}

On the other hand, if $\theta$ was greater than $\theta_{c}$, then light rays will undergo $\overline{n_{o}}$ number of internal reflections back and forth between the reflector surfaces till escaping from the aperture without reaching the receiver, as shown in the last case of Fig. 5. As will be illustrated later on, this parameter is used for studying the effect of the unused part of diffuse radiation on the absorbed energy by the reflector. 

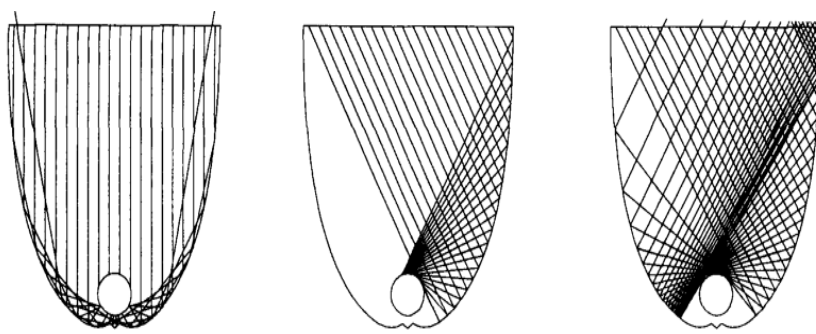

Fig. 5. Ray-trace diagrams for a $30^{\circ}$ acceptance half-angle tubular absorber $\mathrm{CPC}$, rays incident at $0^{\circ}, 29^{\circ}$, and $31^{\circ}$ with the normal to aperture cover [7].

The average number of internal reflections done by light rays outside the acceptance angle can be calculated as found in [8]. It should be noted that this method of calculating $\overline{n_{o}}$ is for CPC with horizontal flat absorber. That's why we put its related equations in Appendix to keep this section organized. Unfortunately there weren't any other alternative methods in literature to calculate $\overline{n_{o}}$ for CPC with tubular absorber.

However, there is no need to correct its value which is expected to differ a little from that for the cylindrical absorber configuration, as this parameter won't affect the overall performance of the collector obviously. We'd like to ensure that the concept of the average number of reflections is used to give a simplified approximation to the actual reflector's behaviour [2].

Ideal concentrators' design, as in Fig. 2, shows that the receiver must touch the reflector. Nevertheless, in practical CPC designs a gap is introduced between the reflector and the absorber to facilitate the assembly of the collector and to reduce the conductive heat losses from the absorber, because a reflector made of aluminum sheet will act as an efficient cooling fin if it was in direct contact with the absorber [9].

Since this gap will cause optical losses which must be minimized, we are then going to select the optimum design between two alternatives. The first one is displacing the absorber with a certain distance $(\mathrm{g})$ vertically upwards from its original position, as shown in Fig. 6. The gap optical losses factor associated with that choice is.

$$
p=1-\frac{g}{\pi R_{r}}
$$

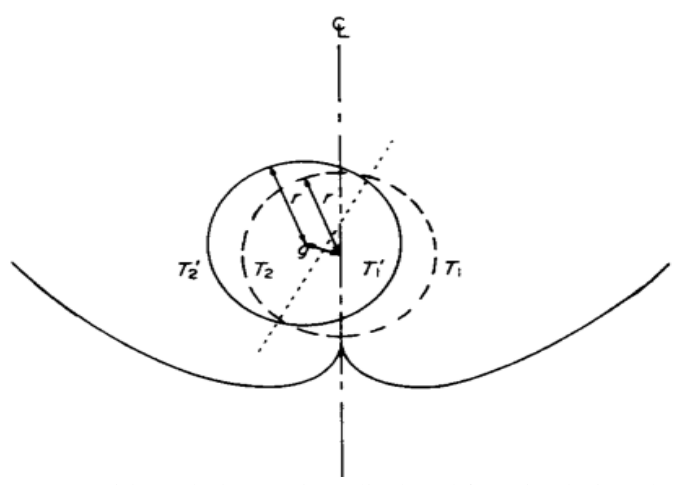

Fig. 6. A CPC with a tubular receiver displaced from its designed position (dashed circle) to another (solid circle) by a distance $\mathrm{g}$ [9].

On the other hand, we can simply truncated the edge of the reflector that touches the absorber, as shown in Fig. 7. The gap optical losses factor for that alternative is given by [9]

$$
p=1-\frac{1}{\pi}\left\{\sqrt{\left[\frac{2 g}{R_{r}}+\left(\frac{g}{R_{r}}\right)^{2}\right]}-\cos ^{-1}\left(\frac{R_{r}}{g+R_{r}}\right)\right\}
$$

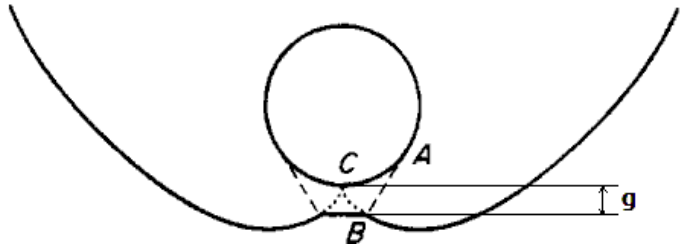

Fig. 7. Truncated reflector to create a gap (g) between the reflector and the receiver [9].

A simple plot was done to observe the gap optical losses factor with different values of $\mathrm{g}$ and $R_{r}$ within our applicable range for both alternatives, as shown in Fig. 8.

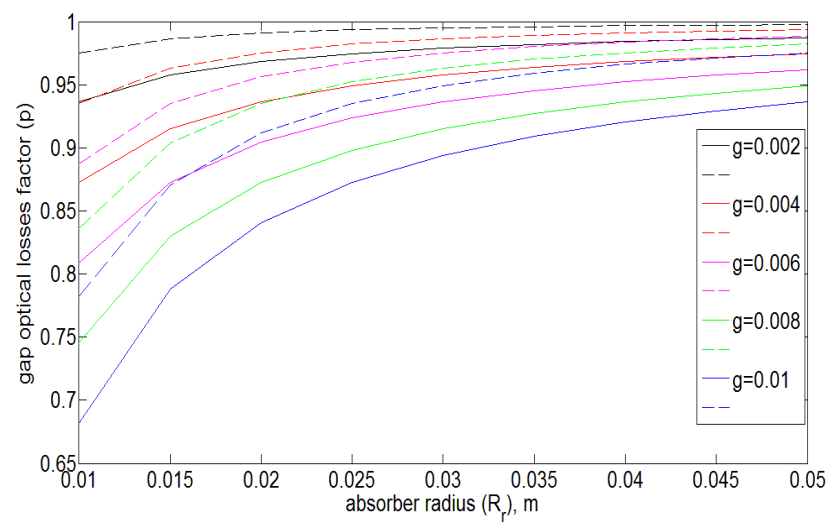

Fig. 8. Gap optical losses with different values of $\mathrm{g}$ and $R r$, first alternative is expressed as solid line while the dashed line is for the second alternative.

It can be clearly seen that truncating the edge of the reflector near the absorber (i.e: the second alternative) provides smaller optical losses rather than those formed by displacing the absorber (i.e: the first alternative). As a result, the second alternative is our choice. An additional feature is modifying the reflector's edge after truncation to resemble a V-like groove, as in Fig. 9. This helps to reduce the gap optical losses furthermore [10].

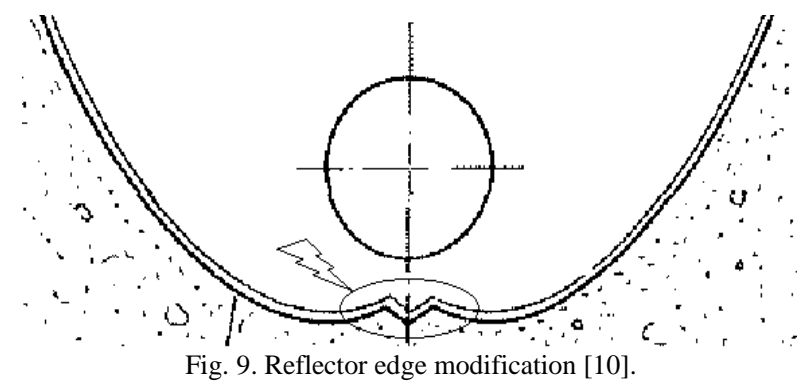

\section{Thermal Analysis}

Before we start discussing the thermal analytical model, it should be considered that the main objective of our thermal analysis is calculating the temperatures of each component of the collector in order to evaluate the useful heat gain, the thermal losses from the CPC and its efficiency. This can be achieved via applying energy balance on each component. Also we should mention the assumptions made to simplify our analysis:

1) All of the collector's components are assembled and aligned accurately and the reflector surfaces are free from any imperfections. The concentration ratio for an untruncated $\mathrm{CPC}$ can be expressed by the well known formula [5] 


$$
C_{\max }=\frac{1}{\sin \theta_{c}}
$$

2) For truncated CPCs, (11) becomes invalid, and the concentration ratio must be calculated as the ratio between aperture and absorber areas, $\mathrm{Aa} / \mathrm{Ar}$.

3) As shown previously, a mean value for the effective reflectivity of the reflector surface is used, $\rho_{m}^{\bar{n}}$, where $\rho_{m}$ is the actual value of the reflectance; taking into our consideration the multiple internal reflections $(\bar{n})$ accomplished by the incident radiation within the acceptance angle before reaching the absorber. A similar value, $\rho_{m}^{\overline{n_{o}}}$, is used for radiation outside the acceptance angle.

4) Solar radiation beam absorptivity, transmissivity and reflectivity of all components are taken to their mean values irrespective of the beam radiation incidence angle or the component's temperature. They are also assumed to be equal to the diffuse ones.

5) Only the absorber, which is selectively coated, has its emmissivity (absorptivity) function of its temperature depending on the coating type.

6) Being ineffective to the overall performance, third and higher-order reflections of the radiation are neglected [2].

7) The temperature variation along the length of the collector is neglected (i.e: one dimensional model). The temperature acquired by a certain component of the collector and calculated through energy balance on it, is considered to be the average value of the actual temperature distribution along that component.

8) The reflector and the glass cover are assumed to be smooth and pure specular surfaces.

9) The glass cover is assumed to be opaque to infra-red (IR) radiation.

10) Although end losses occur in most solar collectors, but it will be neglected in our study.

11) The flow inside the absorber tube is fully developed.

Two types of energies are associated with the energy balance. First of all we have a part of the incident solar energy absorbed by each component. This will lead to a temperature rise of the $\mathrm{CPC}$ components giving chance to radiative and convective heat exchanges to occur, either between them and each other or between them and the ambient. Various forms of heat fluxes are shown in Fig. 10.

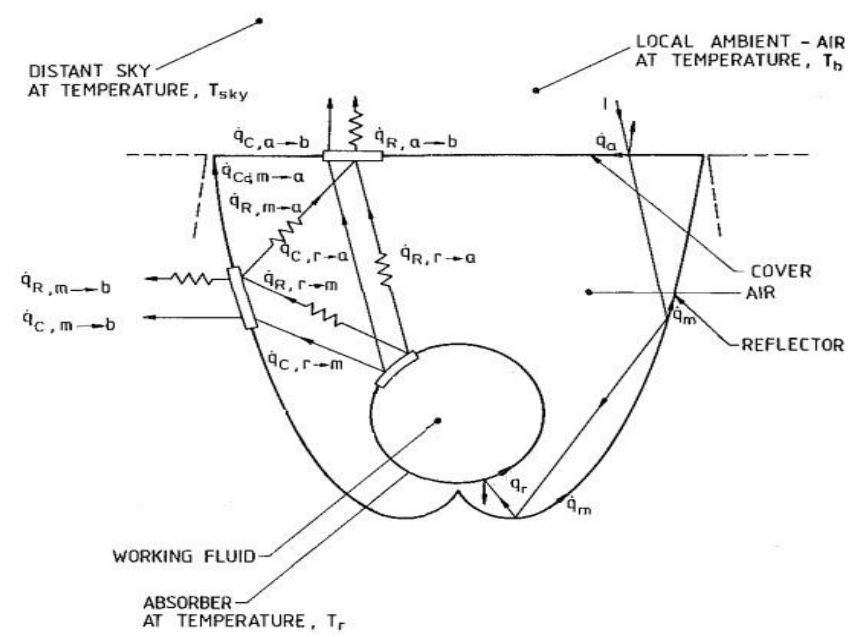

Fig. 10. Heat fluxes and exchange rates between collector components [2].
The part of the incident solar radiation absorbed by the cover is given by [1]

$$
\begin{gathered}
\dot{q_{a}}=I_{\text {tot }} \alpha_{a}\left[1+\tau_{a} \rho_{r} \rho_{m}^{2 \bar{n}}\right], \mathrm{W} / \mathrm{m}^{2} \\
I_{\text {tot }}=F I_{b} \cos \theta+I_{d}, \mathrm{~W} / \mathrm{m}^{2} \\
\left(\beta-\theta_{c}\right) \leq \tan ^{-1}\left(\tan \theta_{z} \cos \gamma_{s}\right) \leq\left(\beta+\theta_{c}\right)
\end{gathered}
$$

where $I_{b}$ and $I_{d}$ are the normal beam radiation and the diffuse radiation on horizontal surface, respectively, $\theta$ is the incidence angle, $F$ is a control function, which is 1 if the criterion of (14) is met (i.e. the incoming beam radiation is within the acceptance angle) and zero otherwise. As shown in Fig. $11, \beta$ is the tilt angle, while $\theta_{z}$ and $\gamma_{s}$ are the zenith angle and the solar azimuth angle, respectively [5].

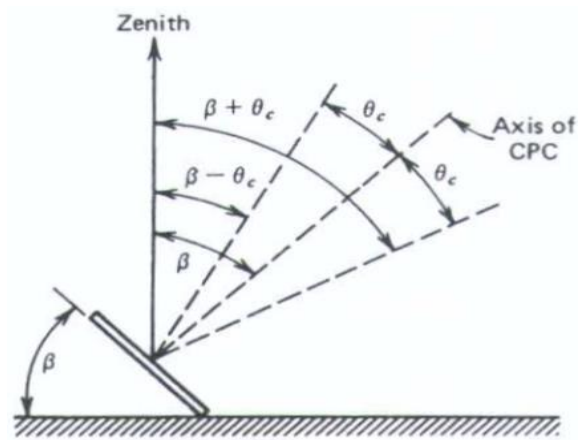

Fig. 11. Projection on a north-south plane of CPC acceptance angles and slope for a CPC on an east-west axis [5].

The second term inside the brackets of (12) represents the portion of radiation that is transmitted through the cover, reflected by the reflector then by the absorber then by the reflector again and finally absorbed by the lower surface of the cover, a second-order effect. The part of incident solar radiation absorbed by the reflector is given by [2]

$$
\begin{aligned}
& q_{m}=I_{u} \tau_{a} \alpha_{m}\left(\bar{n}+\rho_{m}^{\bar{n}} \rho_{r}\left(1-\frac{\theta_{c}}{\pi}\right)\right) \\
& +\left(I_{\text {tot }}-I_{u}\right) \tau_{a} \alpha_{m} \frac{\rho_{m}^{\overline{n_{o}}}-1}{\rho_{m}-1}, \mathrm{~W} / \mathrm{m}^{2}
\end{aligned}
$$

where $I_{u}$ is the useful part of radiation available to the CPC collector

$$
I_{u}=F I_{b} \cos \theta+\frac{I_{d}}{C}, \mathrm{~W} / \mathrm{m}^{2}
$$

The first term of the right-hand side of (15) accounts for the part of the solar radiation absorbed by the reflector, which will accordingly reach the absorber $\left(\theta \leq \theta_{\max }\right)$, and the second term accounts for the absorbed solar radiation entering the $\mathrm{CPC}$ collector at an incidence angle $>\theta_{\text {max }}$. This latter radiation, which is attenuated as being absorbed by the reflector and the top cover, escapes out of the collector after $\overline{n_{o}}$ reflections across the reflector surfaces. Now we can obviously notice that the unused part of the diffuse radiation (i.e: $I_{t o t}-I_{u}$ ) is the main reason why we introduced the term $\overline{n_{o}}$ in the previous section to study the effect of this part of radiation on the CPC performance.

Finally, the part of incident solar radiation absorbed by the absorber is given by [1] 


$$
\dot{q}_{r}=I_{u} \tau_{a} \rho_{m}^{\bar{n}} p \alpha_{r}\left[1+\rho_{r} \rho_{a} \rho_{m}^{2 \bar{n}} p \frac{A_{r}}{A_{a}}\right], \mathrm{W} / \mathrm{m}^{2}
$$

where $A_{r}$ is the absorber area $=2 \pi R_{r} L$. The optical gap losses factor, $p$, as discussed previously can be calculated from (10). The second term inside the brackets of (17) represents the portion of radiation that is transmitted through the cover, reflected by the reflector then by the absorber then by the reflector again then by the cover and finally absorbed by the absorber, a second-order effect. The expressions for the three previous heat fluxes are based on unit area of the top cover.

After the temperature of the CPC components is raised due to the absorbed energy by each, infrared (radiative) and convective heat transfer between them will occur. These rates of heat transfer and the associated thermal resistances can be presented by means of the electric analog shown in Fig. 12. In the coming equations, all the heat-exchange rates are based on the area of the component indicated first in the subscript. Also the subscripts $R, C$ and $C d$ stand for radiative, convective and conductive, respectively.

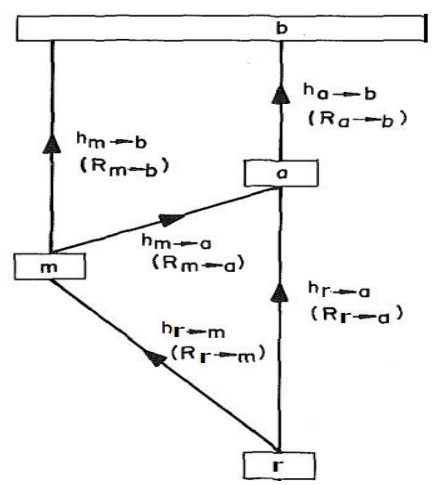

Fig. 12. Electric analog circuit for the CPC collector [2]

The radiation exchange between the absorber and the cover is

$$
\dot{q}_{R, r / a}=\epsilon_{e f f, r / a} \sigma\left(T_{r}^{4}-T_{a}^{4}\right), \mathrm{W} / \mathrm{m}^{2}
$$

where $\sigma$ is the Stefan-Boltzmann, the effective emmissivity between the absorber and the cover is [8]

$$
\epsilon_{e f f, r / a}=\frac{\epsilon_{a} \epsilon_{r} \rho_{m}^{\bar{n}}}{1-\rho_{m}^{2 \bar{n}} \rho_{a} \rho_{r}}
$$

Similarly the radiation exchange between the absorber and the reflector, and between the reflector and the cover, respectively are

$$
\begin{gathered}
\dot{q}_{R, r / m}=\epsilon_{e f f, r / m} \sigma\left(T_{r}^{4}-T_{m}^{4}\right), \mathrm{W} / \mathrm{m}^{2} \\
\dot{q}_{R, m / a}=\epsilon_{e f f, r / m} \sigma\left(T_{m}^{4}-T_{a}^{4}\right) \frac{A_{r}}{A_{m}}, \mathrm{~W} / \mathrm{m}^{2}
\end{gathered}
$$

where [8]

$$
\begin{gathered}
\epsilon_{e f f, r / m}=\frac{1+\rho_{m}^{\bar{n}} \rho_{a}}{1-\rho_{m}^{2 \bar{n}} \rho_{a} \rho_{r}}\left(1-\rho_{m}^{\bar{n}}\right) \epsilon_{r} \\
\epsilon_{e f f, m / a}=\epsilon_{a}\left[\frac{1+\rho_{m}^{\bar{n}} \rho_{r}}{1-\rho_{m}^{2 \bar{n}} \rho_{a} \rho_{r}}\left(1-\rho_{m}^{\bar{n}}\right)+\frac{1-\rho_{m}^{\overline{n_{o}}}}{1-\rho_{m}^{\overline{n_{o}}} \rho_{a}} \frac{A_{a}-A_{r}}{A_{r}}\right]
\end{gathered}
$$

The use of the effective emmissivities in our model is due to the fact that we have radiation exchange between three bodies in an enclosure, which are the absorber, the reflector and the cover. The radiation exchange between the cover and the sky is

$$
\dot{q}_{R, a / b}=\epsilon_{a} \sigma\left(T_{a}^{4}-T_{s k y}^{4}\right), \mathrm{W} / \mathrm{m}^{2}
$$

where in [11]

$$
T_{s k y}=T_{b}-8, K
$$

The values of the absorptance, reflectance, and emittance for (18) to (24) (i.e: infrared exchange) refer to the infrared region of the electromagnetic spectrum, whereas for (12), (15) and (17) (i.e: solar energy absorption) the values of the same parameters refer to the whole solar radiation spectrum.

The other mode of heat transfer is the convective heat loss from each component. The convection heat losses from the absorber to the cover is

$$
\dot{q}_{C, r / a}=h_{C, r / a}\left(T_{r}-T_{a}\right), \mathrm{W} / \mathrm{m}^{2}
$$

where in [12]

$$
\begin{gathered}
h_{C, r / a}=\frac{k_{a i r} N u_{r / a}}{H^{*}}, \mathrm{~W} / \mathrm{m}^{2} . \mathrm{K} \\
N u_{r / a}=0.398 \frac{G r^{(0.1825+0.0736 \cos (\beta-45))}}{(1.24+0.66104 \cos (\beta-45))}\left(\frac{H^{*}}{W / 2}\right)^{0.365} \\
G r=\frac{g \beta_{\text {air }}\left(T_{r}-T_{a}\right) H^{* 3}}{v_{a i r}^{2}}
\end{gathered}
$$

The air properties, $\beta_{\text {air }}, v_{\text {air }}$ and $k_{\text {air }}$, are evaluated at $T_{\text {avg }}$ $=\left(T_{a}+T_{r}\right) / 2$. The characteristic length $H^{*}$ is the height from the top of the receiver to the aperture cover, while $\mathrm{W}$ is the aperture width.

The convection heat losses from the absorber to the reflector is

$$
\dot{q}_{C, r / m}=h_{C, r / m}\left(T_{r}-T_{m}\right), \mathrm{W} / \mathrm{m}^{2}
$$

where in [2],

$$
h_{C, r / m}=f_{\text {rat }} h_{C, r / a}, \mathrm{~W} / \mathrm{m}^{2} . \mathrm{K} \text { and } f_{\text {rat }}=0.55
$$

This value of $f_{\text {rat }}$ was found to be appropriate from experimental correlations done by Prapas et al. [13].

The convection heat losses from the cover, which acts like an ordinary horizontal flat plate, to the ambient is

$$
\dot{q}_{C, a / b}=h_{C, a / b}\left(T_{a}-T_{b}\right), \mathrm{W} / \mathrm{m}^{2}
$$

where

$$
\begin{gathered}
h_{C, a / b}=\frac{k_{a i r} N u_{a / b}}{W}, \mathrm{~W} / \mathrm{m}^{2} . \mathrm{K} \\
\left.N u_{a / b}=0.664 \operatorname{Re}^{1 / 4} \operatorname{Pr}^{1 / 3} \text { (laminar: } \operatorname{Re}<50000\right) \\
N u_{a / b}=0.036 \operatorname{Pr}^{\frac{1}{3}}\left(\operatorname{Re}^{0.8}-23000\right)(\text { turbulent: } \mathrm{Re}>50000)(32)
\end{gathered}
$$




$$
R e=\frac{V W}{v_{\text {air }}}, V \text { is the wind speed, } \mathrm{m} / \mathrm{s}
$$

The air properties in the previous equations are evaluated at $T_{a v g}=\left(T_{a}+T_{b}\right) / 2$, and the characteristic length is the aperture width, $W$. In the temperature range from $250 \mathrm{~K}$ to $600 \mathrm{~K}$ the air properties can be adequately computed as a function of temperature via expressions proposed by Rabl [8]

$$
\begin{gathered}
v_{\text {air }}=9.76 \times 10^{-10} T^{1.7}, \mathrm{~m}^{2} / \mathrm{s} \\
k_{\text {air }}=4.86 \times 10^{-4} T^{0.7}, \mathrm{~W} / \mathrm{m} . \mathrm{K}
\end{gathered}
$$

where $\operatorname{Pr} \cong 0.72$ and $\beta_{\text {air }}=\frac{1}{T}, \mathrm{~K}^{-1}$.

The conductive heat loss from the reflector to the top cover is calculated in terms of the reflector mid-plane temperature, $T_{m}$, assuming that a linear temperature gradient exists from that midpoint to the top cover. Hence, the conductive heat transfer from the reflector to the cover can be expressed as [2]

$$
\dot{q}_{C d, m / a}=4\left(\frac{k_{m} s_{m}}{M^{2}}\right)\left(T_{m}-T_{a}\right), \mathrm{W} / \mathrm{m}^{2}
$$

where $\mathrm{k}_{\mathrm{m}}$ and $\mathrm{s}_{\mathrm{m}}$ are the reflector's thermal conductivity and thickness, respectively.

Referring to Fig. 10, we'll find a last term remaining to be considered which is the heat loss from the reflector to the ambient environment $\left(\dot{q}_{m / b}=\dot{q}_{C \cdot m / b}+\dot{q}_{R, m / b}\right)$. This term depends primarily on the insulation condition of the side wall, making it negligible for a well-designed CPC collector. The convective heat loss from the reflector to the ambient is estimated to be one-tenth of that from the aperture to the ambient [3].

Prapas et al. [2] reported that the overall heat transfer coefficient was found to be nearly insensitive to variation of that heat flux. When multiplied by a factor of four, it would increase the overall heat loss coefficient with only $0.5-14 \%$, and consequently decrease the overall efficiency with $0.1-0.5 \%$.

Finally, by applying an energy balance on the absorber, the useful heat gain becomes

$$
\begin{gathered}
q_{u}=\left(\dot{q}_{r}-h_{\text {tot }}\left(T_{r}-T_{b}\right)\right) * A_{a} * f_{\text {end }} \\
=\frac{T_{r}-T_{\text {mean }}}{\frac{\ln \left(R_{r} / R_{i}\right)}{2 \pi k_{W} L}+\frac{1}{h_{i}\left(2 \pi R_{i} L\right)}}=\dot{m} C_{p}\left(T_{o}-T_{i}\right), \mathrm{W}
\end{gathered}
$$

where:

$h_{\text {tot }}$ is the overall heat loss coefficient from the absorber surface to the ambient, $\mathrm{W} / \mathrm{m}^{2} . \mathrm{K}$.

$T_{i}, T_{o}$ and $T_{\text {mean }}$ are the inlet, outlet and mean fluid temperatures, respectively.

$h_{i}$ and $\dot{m}$ are the internal fluid heat transfer coefficient and the mass flow rate, respectively.

$R_{i}$ and $k_{w}$ are the pipe internal radius and thermal conductivity, respectively.

$f_{\text {end }}$ accounts for the end losses and assumed to be unity.

Recalling the electric analog circuit shown in Fig. 12, we can calculate the overall heat loss coefficient. The thermal resistance corresponding to a certain type of heat flux arising between two collector components $i$ and $j$ is

$$
R_{R(C)(C d), i / j}=\frac{T_{i}-T_{j}}{q_{R(C)(C d), i / j} * A_{i}}, \mathrm{~K} / \mathrm{W}
$$

The total resistance between each two collector components $i$ and $j$ can be simply expressed as the equivalent resistance to two parallel resistances

$$
\frac{1}{R_{i / j}}=\frac{1}{R_{R, i / j}}+\frac{1}{R_{C(C d), i / j}}
$$

Now the total thermal resistance between the absorber and the ambient can be evaluated, with the aid of the star to delta conversion analogical relations. And finally the overall heat loss coefficient per unit aperture area will be

$$
h_{t o t}=\frac{1}{R_{t o t} * A_{a}}, \mathrm{~W} / \mathrm{m}^{2} \cdot \mathrm{K}
$$

The internal fluid heat transfer coefficient can be calculated using the well-known formulas of forced convection internal flow inside a smooth cylinder with uniform heat flux under laminar, transition and turbulent conditions [14],

$$
\begin{gathered}
N u_{i}=\frac{h_{i}\left(2 R_{i}\right)}{k_{f}}=4.36 \quad(\text { laminar: } \operatorname{Re}<2300) \\
=\frac{(f / 8)(R e-1000) P r}{1+12.7(f / 8)^{\frac{1}{2}}\left(\operatorname{Pr}^{\frac{2}{3}}-1\right)}(\text { transition: } 2300<\operatorname{Re}<10000)(42) \\
\left.=0.023 \operatorname{Re}^{4 / 5} \operatorname{Pr}^{0.4} \quad \text { (turbulent: } \operatorname{Re}>10000\right)
\end{gathered}
$$

where $R e=\frac{4 \dot{m}}{\mu\left(2 \pi R_{i}\right)}$ and the fluid properties are calculated at $T_{\text {mean }}=\left(T_{i}+T_{o}\right) / 2$. The friction factor $(f)$ for a smooth tube is

$$
\begin{gathered}
f=\frac{64}{R e} \quad(\operatorname{Re}<2300) \\
f=(0.79 \ln R e-1.64)^{-2} \quad(3000<\operatorname{Re}<5000000)
\end{gathered}
$$

Given the inlet fluid temperature, and with all other parameters known, we can apply an energy balance on the three CPC components; the absorber, the reflector and the cover. The unknown temperatures; $T_{r}, T_{m}, T_{a}$ and $T_{o}$, are initially estimated and recalculated iteratively until the following two equations; energy balance on reflector and cover, respectively, with (40) are satisfied.

$$
\begin{gathered}
q_{R, r / m} A_{r}+q_{C, r / m} A_{r}-q_{R, m / a} A_{m} \\
-q_{C, m / a} A_{m}-q_{m / b} A_{m}+q_{m} A_{a}=0 \\
q_{R, m / a} A_{m}+q_{C, m / a} A_{m}+q_{R, r / a} A_{e}+q_{C, r / a} A_{e} \\
-q_{R, a / b} A_{a}-q_{C, a / b} A_{a}+\dot{q}_{a} A_{a}=0
\end{gathered}
$$

The instantaneous thermal efficiency can be easily evaluated as follows

$$
\eta=\frac{q_{u}}{I_{t o t} * A_{a}}
$$

Finally, the pumping power which plays a big role in 
detecting the overall system efficiency is

$$
\begin{aligned}
\mathbb{P} & =\Delta P * \dot{Q}, \mathrm{~W} \\
\Delta P & =\frac{f L}{D_{i}} \frac{\rho v^{2}}{2}, \mathrm{~Pa}
\end{aligned}
$$

where $\dot{Q}$ is the volume flow rate $=\dot{m} / \rho=\frac{\pi}{4} D_{i}{ }^{2} v, \mathrm{~m}^{3} / \mathrm{s}, v$ is the flow speed and $\Delta P$ is the pressure drop within the tube.

\section{VALIDATION}

A computer program was developed so as to solve the previous equations of the model and give a complete picture of the geometrical, optical and thermal characteristics of any $\mathrm{CPC}$. The validation of that code was achieved by comparing its results with experimental ones of two experiments done previously.

The first experiment was done by Collares-Pereira [10] in Lisbon, Portugal, in 1985. Associated design parameters were introduced into our program and the collector instantaneous efficiency was plotted against the quantity $\left(T_{\text {mean }}-T_{b}\right) / I_{u}$ as a figure of merit. Numerical Results were compared with the experimental ones as shown in Fig. 13. It can be clearly seen that a close agreement exists between experimental and numerical results to within $\pm 2 \%$ of each experimental value.

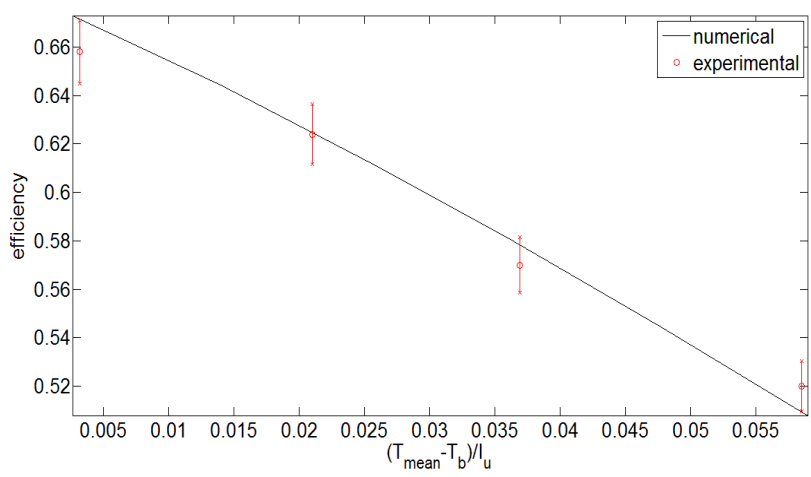

Fig. 13. Numerical and experimental thermal efficiency for the first experiment.

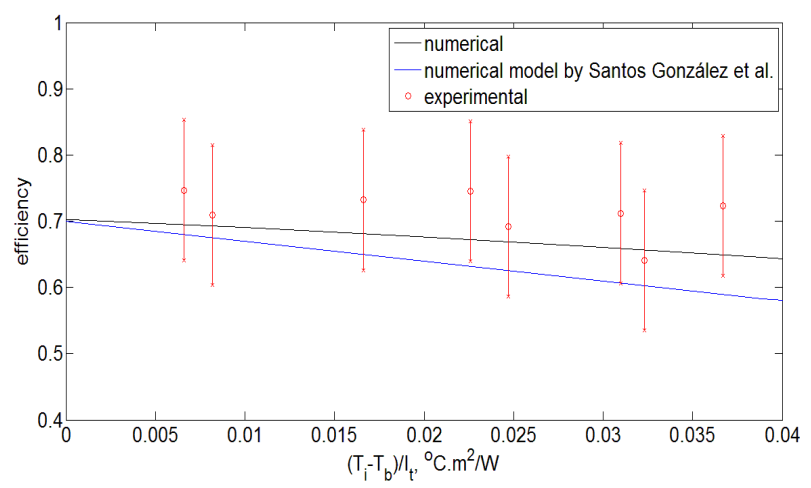

Fig. 14. Numerical and experimental instantaneous thermal efficiency for the second experiment.

The other experiment was set up by Santos-González et al. [15] in Temixco, Mexico, in 2011. After incorporating their design values with our program, the collector instantaneous efficiency was plotted versus the quantity $\left(T_{i}-T_{b}\right) / I_{t}$, as in Fig. 14. Experimental values are previewed along with their associated error bars. A good agreement to within $\pm 10 \%$ occurs between our numerical results and the experimental ones all over the plotted range, better than the numerical model used by Santos-González et al. and discussed by Ortega et al. [16].

\section{EFFECT OF USING TWISTED TAPE INSERTS}

One of the most popular techniques used to enhance the forced convection heat transfer coefficient of internal flow is inserting swirl tapes inside the absorber tube. This heat transfer enhancement (HTE) varies according to the twisted tape geometry, twist ratio $(\mathrm{Z})$ and Renolds number of the internal flow detecting weather it is laminar or turbulent. Also the increase of the friction factor due to the existence of the swiler should be taken into consideration. Thus a compromise between the HTE and the rise in the pumping power is a must.

It can be noticed that in general the HTE by using swirlers is maximum in case of laminar flow, much more than the associated rise in the pumping power. However, it falls obviously in transition and turbulent flow regimes [17], [18].

\section{A. Laminar Flow Regime}

HTE using twisted tapes in laminar flow regime was studied by Wongcharee and Eiamsa-ard [18]. After experimental investigation, they derived empirical equations expressing the variation of Nusselt number and friction factor with Renolds number for both typical twisted tapes and twisted tapes with alternate axis. Those configurations are shown in Fig. 15.

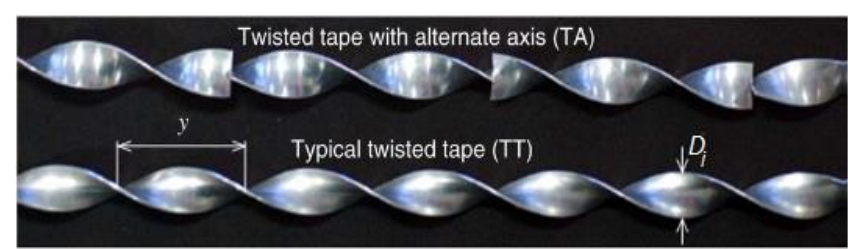

Fig. 15. Twisted tape with alternate axis versus typical twisted tape [18].

The following equations were derived for water flowing inside a tube under uniform heat flux with Renolds number ranging from 830 to 1990 and twist ratios of 3, 4 and 5 .

For typical twisted tape

$$
\begin{array}{r}
N u=0.005 \operatorname{Re}^{1.139} \operatorname{Pr}^{0.4}\left(y / D_{i}\right)^{-0.521} \\
f=6.559 \operatorname{Re}^{-0.303}\left(y / D_{i}\right)^{-0.674}
\end{array}
$$

For twisted tape with alternate axis

$$
\begin{gathered}
N u=0.032 \operatorname{Re}^{0.986} \operatorname{Pr}^{0.4}\left(y / D_{i}\right)^{-0.594} \\
f=12.886 \operatorname{Re}^{-0.304}\left(y / D_{i}\right)^{-0.896}
\end{gathered}
$$

where $y$ is the axial distance of twist pitch with $180^{\circ}$ of rotation and the twist ratio $Z=y / D_{i}$.

We simply replaced (44) - (48) with the previous equations over the valid range of Renolds number and twist ratios, and monitored how the HTE will affect the CPC thermal efficiency at different mass flow rates, inlet temperatures, twist ratios and concentration ratios. In 
addition, the rise in the pumping power due to twisted tape insertion was previewed. It should be noted that the CPC collector specifications shown in Table II were used in this analysis. Some of those were adopted from Prapas et al. [2]

TABLE II: CPC COLLECTOR SAMPLE PARAMETERS

\begin{tabular}{|c|c|c|c|c|}
\hline Name & & symbol & \multicolumn{2}{|c|}{ value } \\
\hline tilt angle (deg) & & $\beta$ & \multicolumn{2}{|c|}{30} \\
\hline truncation ratio & & $H_{t} / H$ & \multicolumn{2}{|c|}{$1 / 3$} \\
\hline absorber outer radius (m) & & $R_{r}$ & \multicolumn{2}{|c|}{0.027} \\
\hline absorber inner radius $(\mathrm{m})$ & & $R_{i}$ & \multicolumn{2}{|c|}{0.025} \\
\hline optical losses factor & & $p$ & \multicolumn{2}{|c|}{0.95} \\
\hline reflector thickness $(\mathrm{m})$ & & $S_{m}$ & \multicolumn{2}{|c|}{0.0003} \\
\hline reflector thermal conductivity $\left(\mathrm{W} / \mathrm{m}^{2} . \mathrm{K}\right)$ & & $k_{m}$ & \multicolumn{2}{|c|}{238} \\
\hline wind speed $(\mathrm{m} / \mathrm{s})$ & & V & \multicolumn{2}{|c|}{3} \\
\hline absorber thermal conductivity $\left(\mathrm{W} / \mathrm{m}^{2} \cdot \mathrm{K}\right)$ & & $k$ & \multicolumn{2}{|c|}{238} \\
\hline Prandtl number for air & & $P r$ & \multicolumn{2}{|c|}{0.72} \\
\hline normal beam radiation $\left(\mathrm{W} / \mathrm{m}^{2}\right)$ & & $I_{b}$ & \multicolumn{2}{|c|}{953} \\
\hline diffuse radiation $\left(\mathrm{W} / \mathrm{m}^{2}\right)$ & & $I_{d}$ & \multicolumn{2}{|c|}{227} \\
\hline ambient temperature $\left({ }^{\circ} \mathrm{C}\right)$ & & $T_{b}$ & \multicolumn{2}{|c|}{20} \\
\hline incidence angle (deg) & & $\theta$ & \multicolumn{2}{|c|}{ zero } \\
\hline half acceptance angle (deg) & & $\theta_{c}$ & \multicolumn{2}{|c|}{$30,15,10$} \\
\hline mass flow rate $(\mathrm{kg} / \mathrm{s})$ & & $\dot{m}$ & \multicolumn{2}{|c|}{ variable } \\
\hline inlet temperature $\left({ }^{\circ} \mathrm{C}\right)$ & & $T_{i}$ & \multicolumn{2}{|c|}{ variable } \\
\hline collector length $(\mathrm{m})$ & & $\mathrm{L}$ & \multicolumn{2}{|c|}{ variable } \\
\hline Radiative properties of components & \multicolumn{2}{|c|}{ solar } & \multicolumn{2}{|c|}{ infrared } \\
\hline reflector reflectivity & $\overline{\rho_{m}}$ & 0.9 & $\rho_{m}$ & 0.5 \\
\hline reflector absorptivity & $\alpha_{m}$ & 0.1 & $\epsilon_{m}$ & 0.5 \\
\hline cover reflectivity & $\rho_{a}$ & 0.06 & $\rho_{a}$ & 0.05 \\
\hline cover absorptivity & $\alpha_{a}$ & 0.04 & $\epsilon_{a}$ & 0.9 \\
\hline cover transmissivity & $\tau_{a}$ & 0.9 & $\tau_{a}$ & 0.05 \\
\hline absorber absorptivity & $\alpha_{r}$ & 0.9 & $\epsilon_{r}$ & $*$ \\
\hline absorber reflectivity & $\rho_{r}$ & 0.1 & $\rho_{r}$ & $1-\epsilon_{r}$ \\
\hline
\end{tabular}

As shown in Fig. 16, using typical twisted tape increased the thermal efficiency with $2.7 \%$ at inlet temperature of 40 ${ }^{\circ} \mathrm{C}$. The efficiency enhancement increased with the inlet temperature till a value of $3.2 \%$ at $80{ }^{\circ} \mathrm{C}$. That's due to the fact that as the inlet temperature increases, water viscosity decreases, then Renolds number and Nusselt number increases above the constant 4.36 level for smooth tube under uniform heat flux and laminar flow conditions. If we used the twisted tape with alternate axis, a greater rise in the efficiency with $3.5 \%$ occurred at inlet temperature of $40{ }^{\circ} \mathrm{C}$, reaching $3.7 \%$ at inlet temperature of $80{ }^{\circ} \mathrm{C}$.

When comparing different values of twist ratio, it was found that decreasing it from 5 to 4 or from 4 to 3 just caused a slight increase in the efficiency with about $0.25 \%$ and $0.14 \%$ for typical twisted tape and twisted tape with alternate axis, respectively, at inlet temperature of $40{ }^{\circ} \mathrm{C}$.

On the other hand, the pumping power, as illustrated in Fig. 17, decreases with the increase of the inlet temperature. Keeping the flow rate constant, the pumping power will be directly proportional only to the friction factor which decreases with the increase of Renolds number for both smooth tube and tube with tape inserts. At inlet temperature of $60{ }^{\circ} \mathrm{C}$, inserting a typical twisted tape with $Z=5$ in the smooth tube quadruples the pumping power. Decreasing the twist ratio to 4 and 3 grows the pumping power up to 4.5 and 5.5 times that for a smooth tube, respectively. As for the twisted tape with alternate axis, its usage with $Z=5$ makes the pumping power 5.3 times that for a smooth tube, which is slightly smaller than that with a $Z=3$ typical twisted tape. Further lessening of the twist ratio to 4 and 3 multiplies the pumping power by a factor of 6.5 and 8.4 , respectively.
Despite appearing very small, in the order of $10^{-5}$, values of the power just help for comparison between different configurations. These small values arise from the small collector length and relatively big inner diameter. Thus using CPC arrays either in series or in parallel and diminishing the absorber diameter will magnify the effect of using twisted tapes on the mounting pumping power consumed and overall system efficiency.

An important parameter which evaluates the usage of swirlers through considering the HTE and the pressure drop increase altogether, is the thermal performance factor. Based on the same pumping power with and without swirlers, the thermal performance factor is defined as

$$
\xi=\left(\frac{N u_{\text {with swirler }}}{N u_{\text {without swirler }}}\right) /\left(\frac{f_{\text {with swirler }}}{f_{\text {without swirler }}}\right)^{1 / 3}
$$

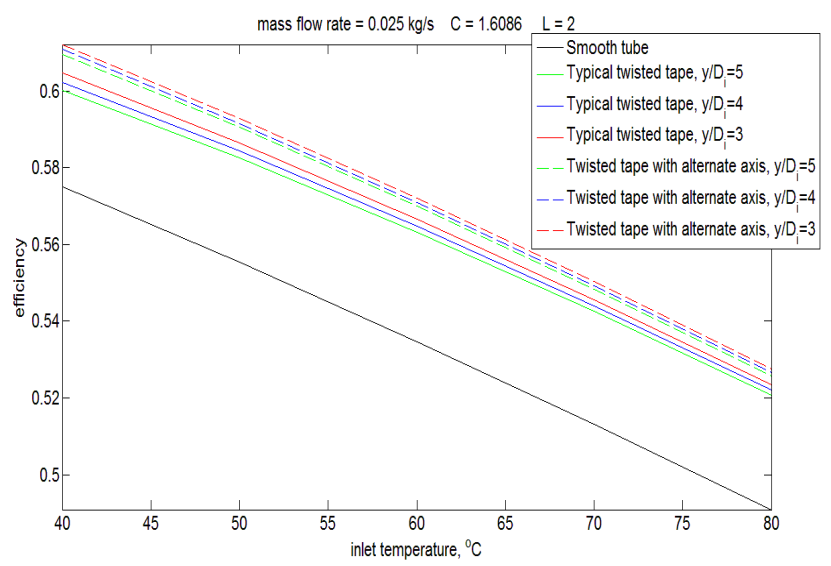

Fig. 16. CPC thermal efficiency versus inlet temperature using different twisted tape configurations (laminar regime).

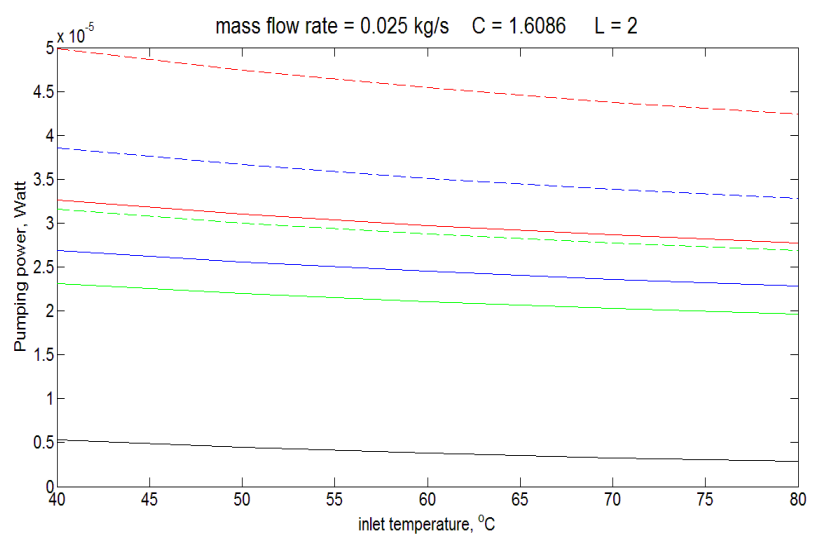

Fig. 17. Pumping power versus inlet temperature using different twisted tape configurations (laminar regime).

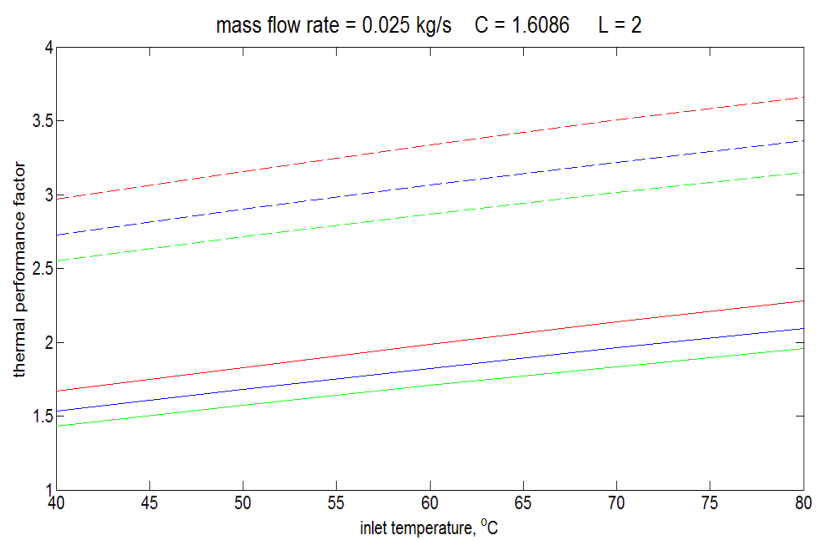

Fig. 18. Thermal performance factor versus inlet temperature using different twisted tape configurations (laminar regime). 
It can be clearly seen that the thermal performance factor, as plotted in Fig. 18, increases with the rise in the inlet temperature, which gives an indication that using swirlers is favorable at elevated inlet temperatures. Also using twisted tapes with alternate axis instead of typical twisted tape can nearly double the thermal performance factor.

The effect of the mass flow rate on the HTE is shown in Fig. 19. We can obviously notice that as the flow rate increases the efficiency enhancement rises, as Renolds number increases and thus Nusselt number grows up. At 0.02 $\mathrm{kg} / \mathrm{s}$, the efficiency growth was around $2.6 \%$ and $3.4 \%$ with typical and alternate axis twisted tapes, respectively. Moreover, this rise in the efficiency reached $3.4 \%$ using typical twisted tape and $3.8 \%$ via that with alternate axis at $0.035 \mathrm{~kg} / \mathrm{s}$.

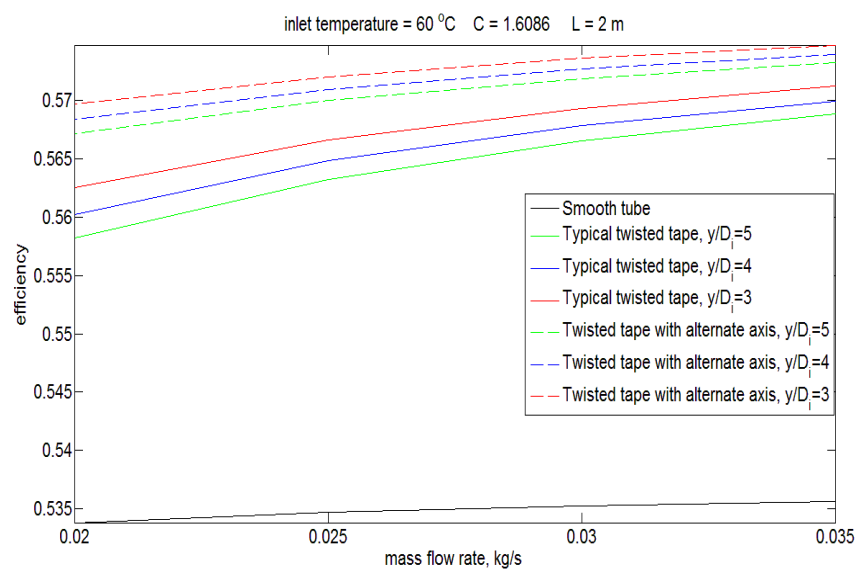

Fig. 19. CPC thermal efficiency versus mass flow rate using different twisted tape configurations (laminar regime).

Unlike what happens when the inlet temperature increases, the pumping power enlarges if we increase the mass flow rate, as shown in Fig. 20. Despite the fact that when Renolds number increases the friction factor decreases, the rise in the flow rate itself -which is directly proportional to Renolds number with a higher order- overcomes this benefit in a manner that makes the pumping power varies directly with Renolds number.

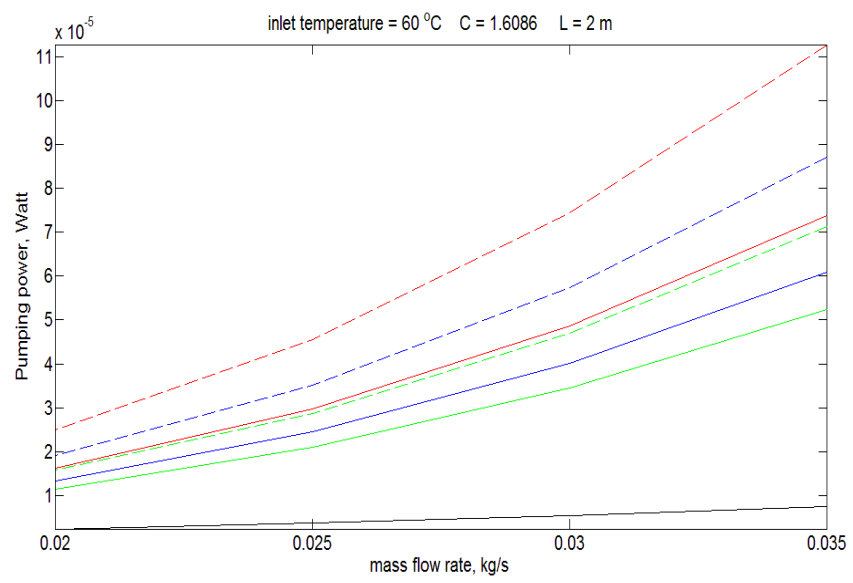

Fig. 20. Pumping power versus mass flow rate using different twisted tape configurations (laminar regime).

At a flow rate of $0.035 \mathrm{~kg} / \mathrm{s}$ we can see that introducing a typical twisted tape with $Z=5, Z=4$ and $Z=3$ makes the pumping power $6.8,7.9$ and 9.6 times that for a tube without swirlers, respectively. Whereas using a twisted tape with alternate axis with $Z=5, Z=4$ and $Z=3$ magnifies the power consumed by a factor of $9.3,11.3$ and 14.6, respectively.

Finally, the thermal performance factor is plotted against the mass flow rate in Fig. 21. As the flow rate increases the thermal performance factor is enhanced, which enables us to achieve better performance via swirlers at bigger mass flow rates. Furthermore, replacing a typical twisted tape with an alternate axis one can approximately double the thermal performance factor.

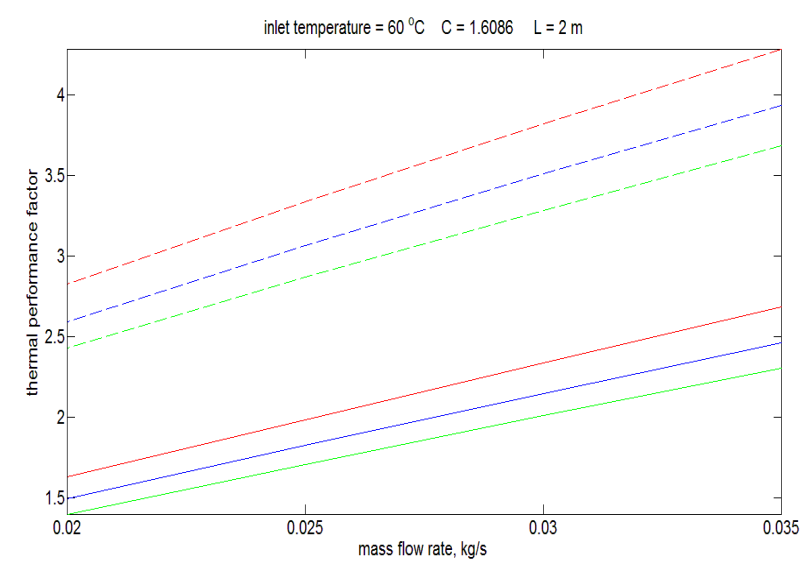

Fig. 21. Thermal performance factor versus mass flow rate using different twisted tape configurations (laminar regime).

A thermal performance factor above unity means that the HTE as a result of twisted tape usage rather than keeping the tube smooth got over the subsequent increase of the friction factor. And as the thermal performance factor increases, swirlers become more preferable. However, a detailed economic study, regarding fixed and running costs, should be made to evaluate the impact of using swirlers on the overall system performance, as will be made in the upcoming case studies.

\section{B. Transition and Turbulent Flow Regimes}

HTE using twisted tapes in transition and turbulent flow regimes was investigated experimentally by Chang et al. [19]. They formulated the governing empirical equations showing the behaviour of Nusselt number and friction factor with Renolds number for both typical twisted tapes and serrated twisted tapes. The serrated twisted tape is shown in Fig. 22.

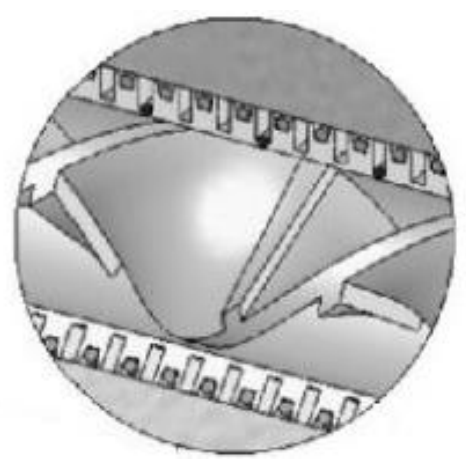

Fig. 22. Serrated twisted tape [19].

The following equations were derived for water flowing inside a tube with Renolds number ranging from 5000 to 25000 and twist ratios of $1.56,1.88,2.81$ till $\infty$,

$$
N u=\left(0.0364+3.66 e^{-1.11 Z}\right) R e^{\left(0.8-0.375 e^{-0.31 Z}\right)} \operatorname{Pr}^{1 / 3}
$$




$$
f=\left(0.07+9.87 e^{-1.81 Z}\right) R e^{\left(-0.08-0.94 e^{-1.23 Z}\right)}
$$

For typical twisted tape

$$
\begin{array}{r}
N u=\left(0.118+5.84 e^{-1.83 Z}\right) R e^{\left(0.73-0.695 e^{-1.26 Z}\right)} \operatorname{Pr}^{1 / 3} \\
\quad f=\left(0.033+0.756 e^{-0.765 Z}\right) R e^{\left(0.166-0.235 e^{-0.524 Z}\right)}
\end{array}
$$

For serrated twisted tape.

We similarly replaced (44)-(48) with the previous equations over the relevant range of Renolds number and twist ratios, then observed the HTE and its effect on the CPC thermal efficiency at different mass flow rates, inlet temperatures and twist ratios.

Fig. 23 shows the variation of the thermal efficiency with inlet temperatures of water flowing through a smooth tube, a tube with typical and serrated twisted tapes. Before starting our discussion, we should mention that till inlet temperature of $50{ }^{\circ} \mathrm{C}$ the flow was in the transition region. After that the flow entered the turbulent zone at higher inlet temperatures. At $40{ }^{\circ} \mathrm{C}$ inlet temperature, the efficiency increase was around $0.27 \%$ at most using serrated twisted tape with $Z=$ 1.5. When the flow was turbulent at inlet temperature of 70 ${ }^{\circ} \mathrm{C}$, and via the same twisted tape, the efficiency rise went down to about $0.22 \%$. It's now obvious that, as predicted, the efficiency enhancement associated with laminar flows is much better than that when the flow is in transition or turbulent regimes. Raising the flow rate to $0.35 \mathrm{~kg} / \mathrm{s}$, as in Fig. 24 , made the flow turbulent throughout the inlet temperatures range, and lessened the efficiency enhancement to only $0.15 \%$, at $60{ }^{\circ} \mathrm{C}$ inlet temperature.

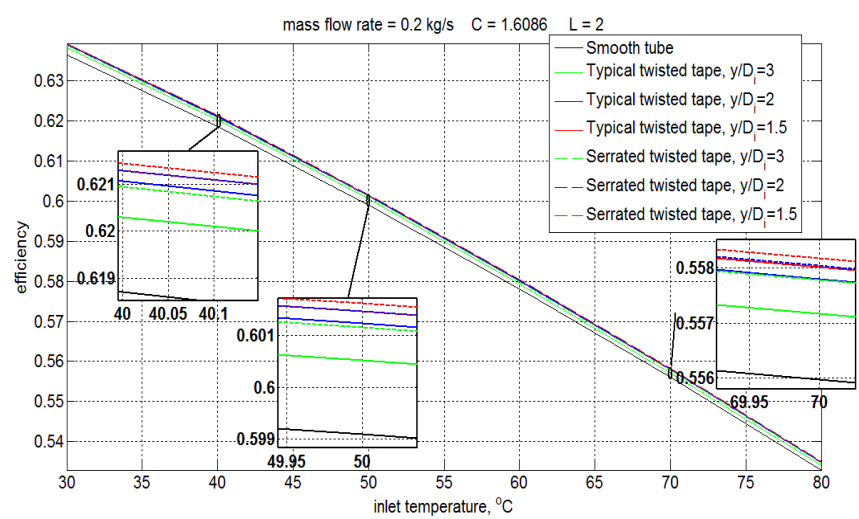

Fig. 23. CPC thermal efficiency versus inlet temperature using different twisted tape configurations (transition + turbulent regimes).

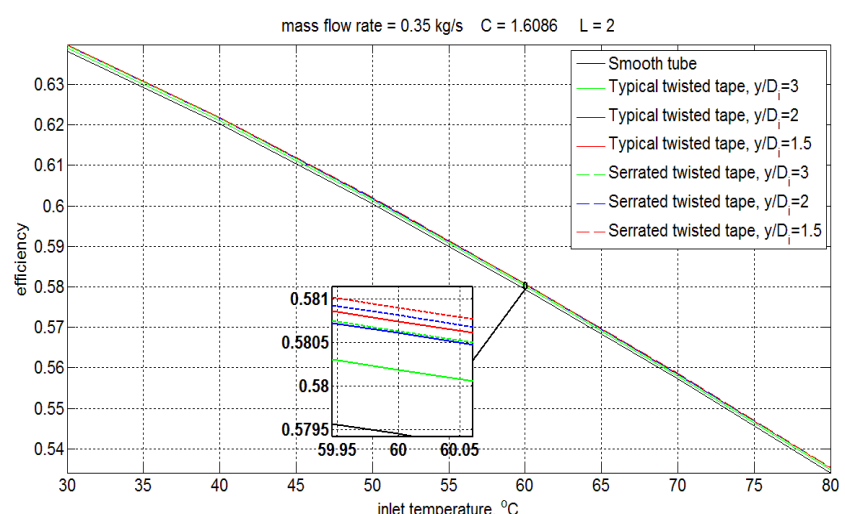

Fig. 24. CPC thermal efficiency versus inlet temperature using different twisted tape configurations (turbulent regime).
The pumping power, as previewed in Fig. 25 and Fig. 26, decreases slightly with the increase in inlet temperature in case of typical twisted tapes, due to the decrease of friction factor with the increase of Renolds number. In contrast, using serrated twisted tapes makes the pumping power increases with inlet temperature. Because serrated twisted tapes are specially characterized by having their friction factor directly proportional with Renolds number, as indicated by (62).

If we compare different twisted tapes configurations, we'll find that at $0.2 \mathrm{~kg} / \mathrm{s}$ and $80{ }^{\circ} \mathrm{C}$ inlet temperature the pumping power with a $Z=1.5$ typical twisted tape is triple that with a smooth tube. In addition, inserting a serrated twisted tape with $Z=3, Z=2$ and $Z=1.5$ will make the pumping power $11.9,15.4$ and 16.9 times that for a smooth tube. The same pumping power behavior retains in case of greater mass flow rates, as in Fig. 26, except that pumping power values are intensified.

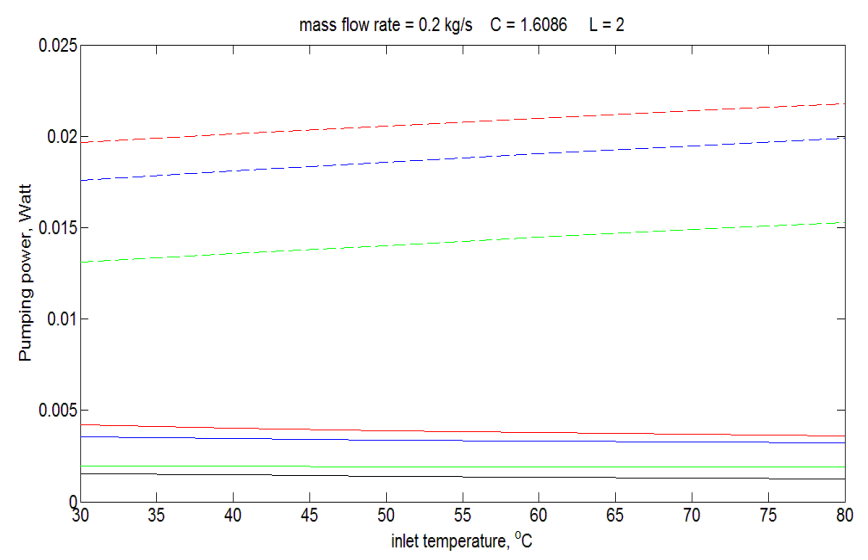

Fig. 25. Pumping power versus inlet temperature using different twisted tape configurations (transition + turbulent regimes).

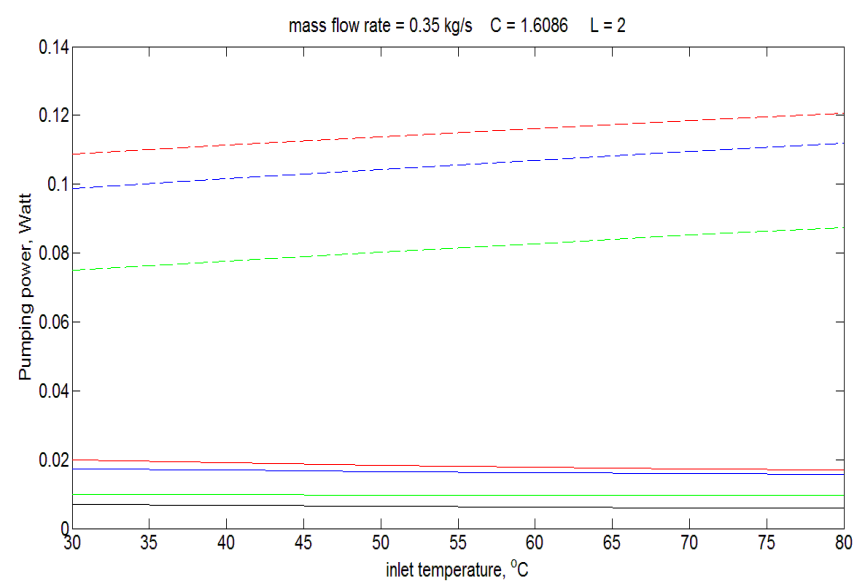

Fig. 26. Pumping power versus inlet temperature using different twisted tape configurations (turbulent regime).

An overall evaluation to using swirlers with flows in transition and turbulent regions can be performed through monitoring the thermal performance factor values, as in Fig. 27 and Fig. 28. In general, the previewed limits of thermal performance factors, which didn't exceed 2.8 by any way, are much smaller than those related with flows in the laminar regime. This agrees with what expected and mentioned previously. A closer inspection shows that increasing the mass flow rate along with using a serrated twisted tape instead of a typical one causes a drop in the thermal performance factor. However, decreasing the twist ratio will give it a rise. Finally, as long as the inlet temperature 
increases the performance factor deteriorates. As a result, swilers with flows having Renolds number above 2300 are unfavorable at large values of mass flow rates and inlet temperatures.

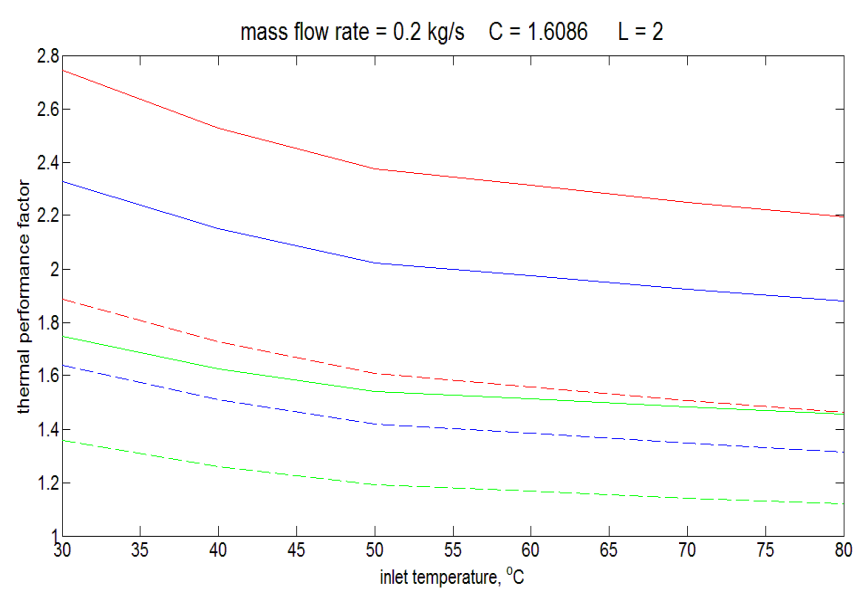

Fig. 27. Thermal performance factor versus inlet temperature using different twisted tape configurations (transition + turbulent regimes).

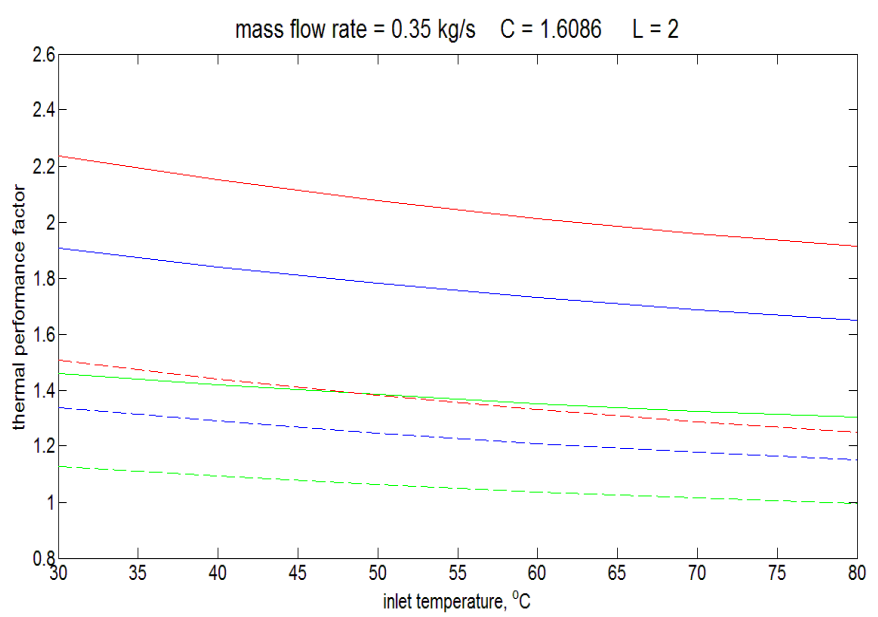

Fig. 28. Thermal performance factor versus inlet temperature using different twisted tape configurations (turbulent regime).

\section{CONCLUSION}

HTE techniques using swirlers performs better when the flow is laminar, being able to increase the CPC thermal efficiency with $3.8 \%$ and achieve a thermal performance factor of 4. While their usage with flows in transition or turbulent regions can hardly enhance the efficiency with $0.27 \%$ with a maximum thermal performance factor of 2.8 . Extending our study to cover CPC collectors with evacuated tubular receivers and discovering the effect of other HTE mechanisms like employing nanofluids can be performed.

\section{APPENDIX}

Having the truncation ratio and acceptance half-angle known, the average number of internal reflections outside the acceptance angle, $\overline{n_{o}}$, for a CPC with flat absorber can be calculated as follows [8]

$$
\overline{n_{o}}=\frac{1}{1-\sin \theta_{c}} \frac{A_{m}}{A_{a}}\left(1-E_{d}(1+C)\right)+\frac{A_{m}}{A_{a}} C E_{d}
$$

where

$$
\begin{gathered}
\frac{A_{m}}{A_{a}}=\left[\left(1+\sin \theta_{c}\right) \ln \left[\frac{x+\sqrt{\left(1+\sin \theta_{c}\right)^{2}+x^{2}}}{\cos \theta_{c}+\sqrt{2\left(1+\sin \theta_{c}\right)}}\right]\right. \\
\left.+x \sqrt{1+\left(\frac{x}{1+\sin \theta_{c}}\right)^{2}}-\frac{\sqrt{2} \cos \theta_{c}}{\sqrt{1+\sin \theta_{c}}}\right]\left(\frac{1}{C}\right) \\
x=\left(\frac{1+\sin \theta_{c}}{\cos \theta_{c}}\right)\left(-\sin \theta_{c}+\left(1+\frac{H_{t}}{H} \cot ^{2} \theta_{c}\right)^{1 / 2}\right) \\
C=2 x \cos \theta_{c}-\frac{x^{2}}{1+\sin \theta_{c}} \sin \theta_{c}+\sin \theta_{c}-\cos ^{2} \theta_{c} \\
E_{d}=\frac{1}{2}-\frac{A_{a}}{A_{m}} \frac{x^{2}-\cos ^{2} \theta_{c}}{2 C\left(1+\sin \theta_{c}\right)}
\end{gathered}
$$

\section{ACKNOWLEDGMENT}

Valuable support from Mechanical Power Department heat transfer staff and Dr. Essam Elhannouny's help are kindly acknowledged.

\section{REFERENCES}

[1] C. K. Hsieh, "Thermal analysis of CPC collectors," Sol. Energy, vol. 27, pp. 19-29, 1981

[2] D. E. Prapas, B. Norton, and S. D. Probert, "Thermal design of compound parabolic concentrating solar energy collectors," J. Sol. Energy Eng., vol. 109, pp. 161-168, 1987.

[3] A. F. Kothdiwala, B. Norton, and P. C. Eames, "The effect of variation of angle of inclination on the performance of low-concentration-ratio compound parabolic concentrating solar collectors," Sol. Energy, vol. 55, no. 4, pp. 301-309, 1995.

[4] W. R. Mcintire, "Truncation of nonimaging cusp concentrators," Sol. Energy, vol. 23, pp. 351-355, 1979.

[5] J. A. Duffie and W. A. Beckman, Solar Engineering of Thermal Processes, 4th ed. New Jersy: John Wiley \& Sons, 2013, ch. 7.

[6] M. J. Carvalho, M. Collares-Pereira, J. M. Gordon, and A. Rabl, "Truncation of CPC solar collectors and its effect on energy collection," Sol. Energy, vol. 35, no. 5, pp. 393-399, 1985.

[7] P. C. Eames and B. Norton, "Validated, unified model for optics and heat transfer in line-axis concentrating solar energy collectors," Sol. Energy, vol. 50, no. 4, pp. 339-355, 1993.

[8] A. Rabl, "Optical and thermal properties of compound parabolic concentrators," Sol. Energy, vol. 18, pp. 497-511, 1976.

[9] A. Rabl, "Practical design considerations for CPC solar collectors," Sol. Energy, vol. 22, pp. 373-381, 1979.

[10] M. Collares-Pereira, "Description and testing of a non-evacuated $1.5 \mathrm{XCPC}$ collector thermal performance comparison with other collector types," J. Sol. Energy Eng., vol. 107, pp. 277-280, 1985.

[11] R. Forristall, "Heat transfer analysis and modeling of a parabolic trough solar receiver implemented in engineering equation solver,' NREL, 2003.

[12] P. C. Eames and B. Norton, "Detailed parametric analyses of heat transfer in CPC solar energy collectors," Sol. Energy, vol. 50, no. 4, pp. 321-338, 1993.

[13] D. E. Prapas, B. Norton, P. E. Melidis, and S. D. Probert, "Convective heat transfers within air spaces of compound parabolic concentrating solar-energy collectors," Appl. Energy, vol. 28, pp. 123-135, 1987.

[14] F. Incropera, T. Bergman, A. Lavine, and D. Dewitt, Fundamentals of Heat and Mass Transfer, 7th ed. John Wiley \& Sons, 2011, ch. 8.

[15] I. S. González, N. Ortega, V. H. Gómez, O. G. Valladares, and R. Best, "Development and experimental investigation of a compound parabolic concentrator," Int. J. Energy Res., no. 36, pp. 1151-1160, 2011.

[16] N. Ortega, O. García-Valladares, R. Best, and V. H. Gómez, "Two-phase flow modelling of a solar concentrator applied as ammonia vapor generator in an absorption refrigerator," Renew. Energy, vol. 33, pp. 2064-2076, Sep. 2008.

[17] M. R. Rao, "Heat transfer augmentation for the flow of a viscous liquid in circular tubes using twisted tape inserts," International J. Heat Mass Transf., vol. 39, no. 17, pp. 3547-3557, 1996.

[18] K. Wongcharee and S. Eiamsa-ard, "Friction and heat transfer characteristics of laminar swirl flow through the round tubes inserted with alternate clockwise and counter-clockwise twisted-tapes," Int. Commun. Heat Mass Transf., vol. 38, no. 3, pp. 348-352, 2011.

[19] S. W. Chang, Y. J. Jan, and J. S. Liou, "Turbulent heat transfer and pressure drop in tube fitted with serrated twisted tape," Int. J. Therm. Sci., vol. 46, pp. 506-518, 2007. 
M. H. Eldakamawy was born on November 14,1990 in Saudi Arabia. He graduated from Faculty of Engineering, Cairo University with a BSc degree in mechanical engineering in 2012. Then he is pursuing his MSc degree in mechanical engineering from Faculty of Engineering, Cairo University until now.

$\mathrm{He}$ is a teaching and research assistant at Faculty of Engineering, Cairo University, Mechanical Power Department, from September 2012 till now. He is not required for military service. He taught numerical methods in thermo-fluid engineering systems, heat and mass transfer, refrigeration and air conditioning and mechanical engineering laboratories.
He also has some training experience. He worked in OMATRA Egypt in August, 2009. In July, 2010, he worked in CB\&I Lummus, Cairo office doing piping design \& rotating equipment selection. Then he worked in Egypt Air Training Center with an aeronautics training including maintenance and operation of Boeing, Airbus and Embraer airplanes in September, 2010. In July, 2011, he was with the Khalda Petroleum Company, Salam Field mainly work is making introduction to some petroleum refining processes performed-maintenance of pumps, compressors and other mechanical equipment used in oil and gas plants. Then in September, 2011, he was with the New and Renewable Energy Authority (NREA). His current and previous research interests are renewable energies and thermofluid sciences. 